\title{
La libertad de los esclavos frente a la legislación y las ideas antiesclavistas en el Nuevo Reino de Granada entre la segunda mitad del siglo XVIII y comienzos del XIX
}

\author{
Fabián Leonardo Benavides Silva**
}

Recibido: febrero 8 de 2013 Aprobado: marzo 22 de 2013

R

El presente artículo indaga sobre las vías jurídicas con los cuales contó el negro esclavo para mejorar su condición de vida o conseguir la libertad en el Nuevo Reino de Granada frente a la legislación española (metropolitana o virreinal), entre la segunda mitad del siglo XVIII y comienzos del XIX. Asimismo, se efectúa un "sondeo" respecto a las ideas antiesclavistas que pudieron enarbolar ciertos sectores de la población neogranadina en el periodo objeto de estudio.

Palabras clave: Nuevo Reino de Granada, esclavos, legislación, ideas antiesclavistas, resistencia y fuga.

* Este artículo hace parte de un trabajo de investigación más amplio desarrollado en el año 2004, el cual se tituló: El fugitivo de la hacienda: Cimarronismo en la ciudad de Cartago y en la Villa de Santa Cruz de Mompox. Finales del siglo XVIII. Bogotá: Universidad Nacional de Colombia-Sede Bogotá/Instituto Colombiano de Antropología e Historia-ICANH.

** Historiador y Magíster en Antropología Social, Universidad Nacional de Colombia-Sede Bogotá. Coordinador del Instituto de Estudios Socio-Históricos "Fray Alonso de Zamora" de la Universidad Santo Tomás, Sede Principal. E-mail: fabianbenavides@usantotomas.edu.co 


\title{
Freedom of slaves in the light of legislation and anti-slavery thoughts in the New Kingdom of Granada between the middle of eighteenth century and at the beginning of nineteenth century*
}

\author{
Fabián Leonardo Benavides Silva**
}

\section{Abstract}

This article explores the legal resources which black slaves counted on in order to improve his life style or to obtain his freedom in the New Kingdom of Granada in the light of the Spanish legislation ( metropolitan or viceregal) between the middle of eighteenth century and at the beginning of the nineteenth century. Furthermore, a "poll" was carried out in the New Granada people concerning their anti-slavery thoughts during that time.

Keywords: New Kingdom of Granada, slaves, legislation, anti-slavery thoughts, resistance and scape.

This article is part of a research project carried out in 2004, which is: The fugitive of the farm: Maroonism in Cartago and in la Villa de Santa Cruz de Mompox at the end of eighteenth century. Bogotá: Universidad Nacional de ColombiaBogotá branch /Instituto Colombiano de Antropología e Historia-ICANH.

** Historian and Master in Social Anthropology, Universidad Nacional de Colombia Bogotá branch. Coordinator of the Institute of Socio-HIstorical studies "Fray Alonso de Zamora" at Universidad Santo Tomás, Main branch. E-mail: fabian benavides@usantotomas.edu.co. 


\title{
La liberté des esclaves face à la législation et les idées antiesclavagistes dans le Royaume de la Nouvelle-Grenade entre la deuxième moitié du XVIIle siècle et le début du XIXe siècle*
}

\author{
Fabián Leonardo Benavides Silva**
}

\section{Résumé}

Cet article explore les voies juridiques avec lesquelles a conté le noir esclave pour améliorer sa qualité de vie ou obtenir la liberté au Royaume de la NouvelleGrenade face à la législation espagnole (métropolitaine ou vice royale), lors de la deuxième moitié du XVIIIe siècle et le début du XIXe siècle. De même, l'on mène à bien un "sondage" par rapport aux idées antiesclavagistes qui ont brandi certains secteurs de la population n néogrenadine lors de la période objet d'étude.

Mots clés: Royaume de Nouvelle-Grenade, esclaves, législation, idées antiesclavagistes, resistance et fuite.

* Cet article s'inscrit dans une recherche plus vaste menée à bien lors de l'année 2004, intitulée: El fugitivo de la hacienda: Cimarronismo en la ciudad de Cartago y en la Villa de Santa Cruz de Mompox. Finales del siglo XVIII. Bogotá: Université Nacional de Colombia-Siège Bogota /Institut Colombien d'Anthropologie et d'Histoire-ICANH.

** Historien et Magister en Anthropologie Sociale, Université «Nacional de Colombia» -Siège Bogotá. Coordinateur de I'Institut d'Études Socio-Historiques "Fray Alonso de Zamora" de l'Université Santo Tomás, Siège Principal. E-mail: fabianbenavides@usantotomas.edu.co. 


\section{Antecedentes}

La introducción de esclavos negros comenzó en el Nuevo Mundo desde los primeros años de conquista en el siglo XVI, pero esta no se produjo a escala considerable hasta principios del siglo XVII, al iniciarse la explotación intensiva de minas, plantaciones y haciendas por parte de los colonos. Entre las causas inmediatas que propiciaron dicho proceso se cuenta con la disminución de la población indígena tras su aniquilación directa, sobreexplotación, contagio de las enfermedades traídas por los conquistadores y las propias dinámicas de mestizaje. Esto culminó con una profunda crisis de mano de obra, impulsando a los colonizadores a poner en marcha una serie de medidas orientadas a reemplazar y a preservar la fuerza de trabajo. Este hecho marcó el mayor y más devastador desplazamiento de población en la historia de la humanidad: la deportación de unos 10 a 15 millones de hombres y de mujeres en casi cuatro siglos de colonización (Fogel y Engerman, 1974, p. 15).

Sin embargo, a la par que se produjo la introducción de esclavos negros, estos por su parte no dejaron de oponer tenaz resistencia al régimen colonial. Prueba de lo anterior fueron las constantes fugas individuales o colectivas que protagonizaron los negros esclavos, antes o después, del arribo de los barcos negreros al Nuevo Mundo (Inikori, 1982, pp. 12-20) ${ }^{1}$. Como lo asevera Price, el cimarronismo se constituyó en un fenómeno recurrente y de carácter general para las colonias del Nuevo Mundo, puesto que "parecían brotar nuevas comunidades cimarronas casi tan pronto como eran exterminadas las antiguas, y permanecieron como "la plaga crónica", "la gangrena" de muchas sociedades de plantación, hasta la emancipación final" (1973, p. 14).

Los colonizadores por su parte, se vieron forzados a pedir un armisticio a sus esclavos fugados y "apalencados". De ahí provienen los tratados efectuados en el Brasil, con el Quilombo de Palmares (Reis y Dos Santos, 1996, pp. 9-12); el de Colombia, con el Palenque de San Basilio (Escalante, 1954, p. 12), y en general, los tratados de Cuba, Ecuador, Jamaica, México y Surinam (Price, 1973, p. 13). En la mayoría de estos tratados las autoridades locales no tuvieron otra alternativa que negociar, ofreciendo la libertad o la autonomía territorial a las comunidades cimarronas.

Particularmente para el Nuevo Reino de Granada los movimientos de rebelión esclava y de formación de palenques, se dieron desde los primeros años del siglo XVI, pero estos se agudizaron y multiplicaron a partir de la segunda mitad del siglo XVIII. Según Jaramillo, dicho fenómeno no puede ser considerado como un plan improvisado ni carente de sentido:

1 Con relación a la trata negrera, existe una amplia bibliografía al respecto; sin embargo, para el Continente Americano se destacan los trabajos pioneros de: Brion (1966), El problema de la esclavitud en la cultura occidental; Herbert (1986), La esclavitud africana en América Latina y el Caribe; y para el caso colombiano, véase el libro de Palacios (1973), La trata de negros por Cartagena de Indias. 
En los años comprendidos entre 1750 y 1790, la conflictividad fue tal, que se tiene la impresión de que pudo existir un acuerdo entre los diferentes núcleos de esclavos para llevar a cabo una rebelión general. En efecto en el transcurso, de este periodo hubo palenques en la Costa Atlántica, en Panamá, en Chocó, Antioquia, el Valle del Cauca, Cundinamarca y los Llanos orientales. Los palenques crearon entonces un estado de alarma permanente entre los propietarios y autoridades colombianas (1963, p. 42).

Aunque, Tovar (1992, pp. 10-18) afirma que tal proliferación de palenques hacia finales del siglo XVIII, no significó una crisis política ni social en el sistema colonial neogranadino, sino más bien este fenómeno obedeció a la generalización de un temor de tipo económico por parte de los propietarios de esclavos, ante la posibilidad de perder a sus más preciados bienes en levantamientos o en fugas que los mismos esclavos pudieran emprender. Así, este fenómeno nunca se dio en una escala considerable como sí ocurrió en los Estados Unidos (Brion, 1966), las Antillas inglesas o francesas (Price, 1973), e incluso, en algunas colonias españolas del Caribe (Herbert, 1986).

\section{La situación jurídica del esclavo neogranadino}

En este aparte se establece que la población esclava neogranadina ante la insuficiencia o poca efectividad de las vías jurídicas que posibilitaran la preservación o reconfiguración de sus prácticas culturales ${ }^{2}$, optaron por la confrontación velada como el hecho de evadirse durante las noches para asumir una vida paralela a la llevada por los esclavos, y abierta en el caso de las rebeliones y fugas individuales o colectivas (Díaz, 2009, p. 403), con el fin de establecer su propio "microcosmos" sociocultural y político.

De acuerdo con Tovar (1992, pp. 18-20) el Estado español coadyuvó a restarle poder a los amos respecto a sus esclavos en todas sus colonias de ultramar, al crear y legalizar ciertas "vías jurídicas" mediante las cuales los esclavos pudieron mejorar las condiciones de sus vidas u obtener la libertad. Estas vías jurídicas estaban compuestas a su vez por una serie de disposiciones tanto informales (instituidas por la fuerza de la costumbre) como formales (impuestas por la misma Corona), que inducen a pensar en una población esclava no del todo "desnuda jurídicamente" durante la colonia y sobre todo, hacia finales del siglo XVIII. Las disposiciones jurídicas eran las siguientes:

1. La compra de la libertad por parte del propio esclavo a través de la denominada "Carta de Ahorro" o "de Libertad".

2 Se empleará también del concepto de cultura como praxis expuesto por Bauman, el cual hace referencia "tanto a la invención como a la preservación [de cualquier cultura y en especial de sus prácticas], a la discontinuidad como a la continuidad, a la novedad como a la tradición, a la rutina como a la ruptura de modelos, al seguimiento de las normas como a su superación, a lo único como a lo corriente, al cambio como a la monotonía de la reproducción, a lo inesperado como a lo predecible" (2002, p. 22). 
2. La manumisión "espontánea" que efectuaron algunos amos hacia sus esclavos.

3. El cambio de amo al que podían recurrir los esclavos, siempre y cuando se comprobaran algunos abusos e irregularidades de los primeros, por ejemplo, malos tratos o el hecho de no proveerlos de ropa y de alimentos.

4. La concesión para la población esclava de no trabajar los días festivos ni domingos, según una real cédula del año de 1772, en cuyo tiempo no solo podían descansar o asistir a los actos religiosos, sino establecer una economía propia o un peculio.

5. La Real Cédula de Aranjuez del 31 de Mayo de 1789, compuesta por catorce capítulos en los cuales se contemplaba el tipo de educación, el trato y las ocupaciones que los esclavos debían recibir por parte de sus amos, en tanto ratificaba la "merced" de poder cambiar de amo.

Es necesario anotar que esta serie de disposiciones legales expuestas por Tovar, en realidad no modificaron en forma sustancial la situación jurídica de los esclavos en el Nuevo Reino de Granada y por el contrario, se mantuvo su carácter punitivo o penal (García, 2003, pp. 97-102). Es más, la escasez de canales efectivos para conseguir la libertad no solo fue la nota predominante en la población esclava neogranadina, sino que esta práctica o política coercitiva también imperó y seguramente con mayor fuerza, en las dos principales colonias españolas, Méjico (Davidson, 1973, p. 86) y Perú (Bowser, 1977, pp. 248-253).

Por ejemplo, las "Cartas de Ahorro" o de "Libertad", no fueron fáciles de conseguir al exigir del esclavo toda una vida de ahorro para obtenerla. En el caso de la Provincia de Popayán, Rodríguez (1981, pp. 77-85) ha calculado cuánto debía trabajar un esclavo para obtener su libertad bajo este mecanismo, estableciendo que este recibía un salario de dos reales semanales, en el mejor de los casos, con los cuales al cabo de toda su vida (hasta los 40 o 50 años de edad que era el promedio de vida de un esclavo) lograba acumular los 200 pesos del precio de su "Carta de Ahorro" o de "Libertad"3.

En cuanto a los esclavos manumitidos por algunos amos de ideas filantrópicas debe decirse que fueron más la excepción a la regla como se verá más adelante y otra cosa muy distinta, fue la población libre de color cuyo origen obedeció, más que nada, al mismo proceso de mestizaje de los casi tres siglos de colonización precedentes, el cual se encontraba bien avanzado hacia finales del siglo XVIII. Así las cosas, dicha población libre (de todas las castas sin contar el contingente indígena y blanco) en el Nuevo Reino de Granada sumaban 375.477 almas $(47 \%)$, mientras que la población esclava apenas alcanzaba a las 62.547 personas (7.83 \%) (Tovar, 1992, p. 11). El mismo Díaz (2001, pp. 189-209) estableció que en Santafé hacia la primera mitad del siglo XVIII, las manumisiones fueron toda 
una "parodia de la libertad" y en particular las "manumisiones condicionadas", puesto que la sociedad esclavista santafereña le confirió un significado ambivalente o ambiguo a dicha práctica, al exigir que el esclavo prestara asistencia de forma servil a su antiguo amo o a la familia de este, antes o después de ser manumitido.

La tercera vía jurídica con la que contaron los esclavos señalada atrás (cambio de amo por malos tratos), también estuvo condicionada por la misma efectividad del aparato jurídico-administrativo virreinal, el cual obedeció más a la fuerza de la costumbre (provincial o local) que a las instituciones formales impuestas por la Corona española al respecto (García, 2003, pp. 97-102). Es decir, que a pesar del alto índice de demandas efectuadas por los esclavos frente a los abusos de sus amos durante el periodo colonial, la gran mayoría de estas causas no prosperaron ante las autoridades quienes le dieron una interpretación "flexible" o acomodada a las normas (García, 2003, pp. 97-102; Bernand, 2000, p. 83) y terminaron por privilegiar los intereses de los propietarios (Jaramillo, 1963, pp. 3-62).

Sin lugar a dudas, un factor determinante en la configuración "flexible" del aparato jurídico-administrativo neogranadino, consistió en que el virreinato era grande y sus habitantes pocos, como lo anota Taussig (1979, p. 370), lo cual impidió un "efectivo control" sobre la población. La debilidad e incapacidad del poder central en el control de las cuatro grandes zonas del virreinato (Caribeña, Andina, Sur occidental y Amazónica), fragmentadas a su vez en 11 provincias y una subprovincia (Riohacha), obligó a las autoridades reales o locales a recurrir a la "buena voluntad" de la población en general ${ }^{4}$, puesto que el virreinato no contaba con un pie de fuerza considerable ${ }^{5}$ y el existente se concentraba en: Cartagena, Panamá, Santa Marta y Ríohacha, en espera de una posible agresión extranjera (de piratas o corsarios), o bien para "mermar" en algo la incesante actividad de los contrabandistas 6 .

La debilidad del poder central dejaba inmensas zonas rurales del virreinato sin la presencia simbólica o material del Estado español, estimulando indirectamente una cultura de la ilegalidad, apreciable en los siguientes aspectos: la formación de pueblos arrochelados de todas las castas (mestizos, indios,

$4 \quad$ Uno de los principales factores que acentuó aún más dicha fragmentación territorial en el Nuevo Reino de Granada, fue el lamentable estado de las vías de comunicación. Por ejemplo, un viaje de Cartagena hacia Santafé podía durar, con suerte, 40 días, en tanto que un viaje de Santafé a Popayán duraba aproximadamente de 20 a 30 días, sin cargamento (McFarlane, 1997, pp. 350-355)

5 Por ejemplo, el Regimiento Fijo de Cartagena creció de 621 hombres en 1773 a 3.500 soldados para 1780 (compuesto por el cuerpo de artillería y el cuerpo de veteranos de las milicias de blancos y de pardos), pero este incremento tuvo poca incidencia en las provincias del interior, puesto que no se beneficiaron directamente del respaldo de dicho regimiento, salvo en muy pocas ocasiones (como en el instante que fue necesario sofocar la Revolución Comunera), y por el contrario, veían a Cartagena como una carga fiscal más (Kuethe, 1993).

6 Múnera (1998, pp. 43-50) sostiene que fue tanto y tan escandalosa la actividad del contrabando en el Caribe neogranadino y en especial, hacia la segunda mitad del siglo XVII, pues gran parte de su población se dedicó al jugoso "negocio" sin ningún miramiento de raza o de status social, pese a las "drásticas" políticas del gobierno Borbón al respecto. 
negros y mulatos, entre otros) o de esclavos negros fugados ${ }^{7}$; el auge y el fortalecimiento del contrabando en la Costa Caribe donde participaba toda la población sin miramientos de raza, de estatus, o de condición social, incluyendo la participación de los mismos funcionarios comisionados para detenerlo ${ }^{8}$ y la incapacidad de la propia Iglesia católica en proveer del "pasto espiritual" a los diferentes sectores de la sociedad, e incluso, en las principales capitales de provincia (Rodríguez, 1997, pp. 82-83) ${ }^{9}$.

Respecto a la concesión que tuvieron los esclavos de no trabajar los días festivos ni domingos (de acuerdo a una real cédula del año de 1772), con el fin de que aprovechasen el tiempo en actividades religiosas o económicas, también existen pruebas de que pudo beneficiar más a los propietarios y estar sujeta a la voluntad de estos. Por ejemplo, esta medida dio pie para que los amos no asumieran enteramente su responsabilidad económica respecto a los esclavos, al exigirles que acarrearan con el total o parte de los gastos de manutención con los dineros obtenidos durante estos días de "asueto". En ciudades como Cartagena de Indias hacia la segunda mitad del siglo XVIII, se sabe de algunos esclavos que fueron alquilados por parte de sus amos en el servicio doméstico (en el caso de las mujeres) o en los puertos y haciendas aledañas a la ciudad (con relación a los hombres), naturalmente en beneficio económico de sus propietarios (Bernand, 2000, p. 83).

De igual manera, Díaz (2001, pp. 164-174) ha demostrado que en la ciudad de Santafé de Bogotá durante la primera mitad del siglo XVIII, algunos esclavos lograron, con mucho esfuerzo, tiempo y dedicación, hacerse a una "economía propia y a un peculio", ganando con esto cierta independencia o movilidad social. Sin embargo, la prohibición o el condicionamiento por parte de los amos de dichos mecanismos de ascenso social de los esclavos, también impulsó a varios de estos hacia la insubordinación o la fuga. Este fue el caso de los hacendados de las ciudades de Toro y Cartago, quienes ocultaron el contenido a sus esclavos de la real cédula de 1772. No obstante, unos meses más tarde la población negra tuvo indicios de su promulgación y gradualmente, fueron organizando levantamientos en ambos lugares (durante el mes de enero de 1773), con el fin de que sus amos reconocieran la existencia del documento (Archivo General de la Nación, Bogotá, en adelante AGN, Negros y Esclavos del Cauca, T. III, f. 51r.).

7 Sobre la formación de pueblos de arrochelados y de palenques de negros en la Costa Caribe colombiana durante el periodo colonial, véase por ejemplo, el ya citado libro de Fals (1979 et. al) y para el suroccidente del virreinato se destaca el artículo de Zuluaga (1986).

8 Las propias autoridades encargadas de sancionar esta actividad eran las primeras en participar en ella, como sucedió con el Prior del Consulado de Comercio quien en 1795 fue sorprendido realizando negocios de esta naturaleza y asimismo, no valió que el virrey Mendinueta le pidiera al obispo de Cartagena que amenazara con la excomunión a cualquiera que osara dedicarse al contrabando (Múnera, 1998; Peñas, 1981).

9 Este autor tomó cuatro ciudades representativas (Cali, Tunja, Cartagena y Medellín) del Nuevo Reino de Granada hacia finales del siglo XVIII y consiguió demostrar, entre otras cosas, que el alto número de madres solteras (en algunas de estos lugares alcanzó hasta un $30 \%$ de mujeres en esta condición) se debió en gran medida a la poca efectividad de la Iglesia católica en la enseñanza de sus preceptos y tareas evangelizadoras. Por otro lado, véase también el libro de carácter autobiográfico del padre Joseph Palacios de la Vega (1955), Diario de viajes del padre Joseph Palacios de la Vega entre los indios y negros de la Provincia de Cartagena en el Nuevo Reino de Granada, 1787-1788, en donde se evidencia la incapacidad (simbólica y material) que tuvo la Iglesia en proveer del "pasto espiritual" a las poblaciones ribereñas del río Magdalena. 
Finalmente, la Real Cédula de Aranjuez de 1789, el estatuto que más pretendió proteger a los esclavos de los abusos de sus amos y el que mayor malestar despertó en los propietarios de esclavos (ante el temor de perder poder frente a aquellos), no tuvo una visión piadosa ni digna respecto a la población esclava, sino más bien se inscribió en el plano de la coerción, al tiempo que terminó confinando a los esclavos en las labores más arduas (como el trabajo en los campos) o menos sedentarias (Friedemann, 1993, p. 62). Así, las autoridades reales y virreinales contemplaron que se debían realizar visitas periódicas en las haciendas, a fin de velar por el cumplimento de la real cédula. Sin embargo, la medida encontró gran oposición entre los propietarios de esclavos y se organizaron en Juntas de hacendados, las cuales neutralizaron u obstaculizaron la disposición real, sobre todo, en provincias como Cartagena y Santafé (Tovar, 1992, pp. 21-22). Por ejemplo, en la causa que se le siguió a los esclavos de la Hacienda de San Bartolomé, aledaña a la Villa de Santa Cruz de Mompós, por formar palenque en el año de 1799, se confirma el grado de abandono y sobreexplotación al que seguían expuestos los esclavos, puesto que uno de los negros implicados en la fuga afirmó: "que en tiempos de su difunto amo pasaban hambres, y de[s]nudeces por estar trabajando hasta de noche por la palabra que les había dado de dejarlos libres" (AGN-Bogotá, Negros y Esclavos de Bolívar, t. III, ff. 788v-789v). La promesa de libertad efectuada por el amo, don Martín de Setuaín, es probable que persiguiera un mayor rendimiento en las labores desempeñadas por sus esclavos y asimismo, fuera un intento del amo por conjurar los posibles brotes de levantamientos o de fugas entre los mismos, práctica común de algunos propietarios no solo en el Nuevo Reino de Granada, sino en toda América" (Benavides, 2004 p. 46).

De esta forma, se puede aseverar que las disposiciones o concesiones jurídicas impartidas por la Corona española o el gobierno virreinal, no garantizaron o no posibilitaron que la población esclava neogranadina pudiera preservar, acomodar o reconfigurar su cultura, obligándola a recurrir a una vida paralela y subrepticia (como las celebraciones nocturnas acompañadas de cantos y danzas) respecto a la mirada maniquea o censurante de las autoridades y de los amos (Díaz, 2009, pp. 400-420). Pero, por otro lado, también fue impulsada a llevar a cabo diversas rebeliones y fugas (individuales o colectivas), las cuales pueden contarse entre los actos más importantes de oposición y de resistencia por parte del negro esclavo hacia la sociedad esclavista colonial. Con relación a las fugas de esclavos debe anotarse, que no todas persiguieron la formación de sociedades negras o palenques, al tiempo que la mayoría de estas no alcanzaron o tuvieron poco éxito en su cometido (Bastide, 1969, p. 50).

A pesar de lo anterior, la formación de palenques tendió a multiplicarse en todo el virreinato hacia la segunda mitad del siglo XVIII (como se anotó al comienzo de este artículo), momento en el cual se emitieron más disposiciones jurídicas con relación a los siglos pasados destinadas a proteger a los esclavos, en tanto que empezaron a circular ideas de corte antiesclavista o abolicionistas provenientes del extranjero. De este modo, entre los siglos XVI y XVII se dieron 6 y 8 casos, respectivamente, de formación de palenques en territorio neogranadino, 
mientras que en el siglo XVIII encontramos 12 casos y la mayoría de estos se establecieron hacia la segunda mitad de la centuria (Azopardo, 1992, pp. 41-42).

\section{Las ideas antiesclavistas en el Nuevo Reino de Granada}

De antemano debe dejarse en claro que durante el siglo XVIII las ideas antiesclavistas de parte de los propietarios de esclavos en el Nuevo Reino de Granada, brillaron más por su ausencia tanto en los círculos de eruditos o de estudiosos, como en los contextos de la población blanca en general. Sin embargo, era factible que cualquier propietario de esclavos en agradecimiento por los servicios recibidos por alguno de estos, decidiera liberarlo espontáneamente como sucedió con doña Javiera Londoño y don Lorenzo Agudelo, quienes manumitieron en Antioquia a 125 y a 85 esclavos, respectivamente, promediando el siglo XVIII. No obstante, ninguno de estos actos filantrópicos logró ser llevado a cabo, pues ambos propietarios fueron tomados por dementes (Azopardo, 1992, p. 70).

Contrario a lo que pudiera esperarse de los círculos de eruditos neogranadinos, la historiografía no registra ni un escrito de carácter antiesclavista anterior a la fecha de 1800. Antes bien, encontramos, por ejemplo, que el traductor de los Derechos del Hombre en el Nuevo Reino de Granada, Antonio Nariño, aparte de poseer una esclava, jamás hizo nada por cambiar la condición material o espiritual de los esclavos del virreinato. Es más, Nariño presentó un proyecto al virrey Pedro Mendinueta en el año de 1797, el cual tituló "Ensayo sobre un nuevo plan de administración en el Nuevo Reino de Granada". En este se contemplaron medidas tales como:

[...] Los fondos del pago de los réditos de los vales y de la caja de descuentos para su extinción [...] deberían emplearse en la compra de negros para darlos en arrendamiento a los particulares. [...] Aunque este pensamiento parezca a primera vista no muy acertado, no obstante es, en mi concepto, de muchísima importancia; con el van asegurados los réditos de los vales y la caja de extinción. En el erario va a formarse un nuevo fondo; la agricultura y las nuevas minas van a tomar un nuevo incremento y el Estado va a criar una milicia sin costo, que en caso urgente puede ser de mucha utilidad, empleándola, cuando no todos en las armas, a lo menos en el transporte de municiones y bagajes y en trabajo de fortificaciones, etc. Veamos si será fácil su despacho.

Los hombres que se reciben en arrendamiento, computando los salarios que varían algo en el reino, cuestan al año, sin incluir los días festivos, $\$ 73,2$ reales; y no en todas partes es fácil conseguirlos, lo que retarda y atrasa el cultivo. Los negros, por los gastos de transporte, etc., los pondremos, unos con otros a $\$ 300$, que comparándose con el precio de los vales, que deben correr a un 
$3 \%$, cuesta al año cada negro nueve pesos. Póngaseles el precio de arrendamiento, unos con otros, a \$21 al año; agréguense siete pesos que cuesta su mantenimiento y tres del vestuario y le costarán al arrendatario $\$ 31$. Quiere que la tercera parte de los que recibe le sea inútiles y que se cargue a los útiles, le vendrán a costar $\$ 46,4$ reales, que rebajados a $\$ 73,2$ reales que le cuesta el hombre libre, quedarán a su favor $\$ 26,6$ reales y la incomparable ventaja de tener todo el año trabajadores prontos [...] (Fonnegra, 1982, pp. 13-37) ${ }^{10}$.

Como se comprueba en los fragmentos citados de este escrito, Nariño olvidó el Artículo $1^{\circ}$ de los Derechos del Hombre: "los hombres nacen y permanecen libres e iguales en derechos", al referirse a los negros como simples bienes inmuebles; sin embargo, es posible que el encierro le produjera cierta "amnesia" al respecto, pues en aquel momento se encontraba prisionero en la Real Cárcel de Santafé.

Asimismo, Francisco José de Caldas dejó constancia de su profundo desprecio hacia los africanos en su ensayo "Del influjo del clima sobre los seres organizados" (1808). En este documento Caldas puso en duda las capacidades mentales y la conducta moral de esta población al afirmar que:

El africano de la vecindad del ecuador, sano, bien proporcionado, vive desnudo bajo de chozas miserables. Simple, sin talentos, solo se ocupa con los objetos presentes. Las imperiosas necesidades de la naturaleza son seguidas sin moderación y sin freno. Lascivo hasta la brutalidad, se entrega sin reserva al comercio de las mujeres. Estas, tal vez más licenciosas, hacen de rameras sin rubor y sin remordimientos. Ocioso apenas conoce las comodidades de la vida [...] (Caldas, 1808, p. 205).

El naturalista Jorge Tadeo Lozano en su estudio sobre la "Fauna cundinamarquesa" (1809), aseveró en consonancia con los anteriores criollos ilustrados que los negros eran moral e intelectualmente inferiores a las demás razas ("europeos" e "indios"):

Muchos naturalistas han observado que todas las producciones africanas manifiestan en su hábito y aspecto la aspereza del clima en que han nacido. Los negros son una prueba palpable de esta aserción: su carácter moral se compone de todas aquellas pasiones, que hacen al hombre duro, y poco sociable; en efecto, junto con su extremada robustez, se nota su torpeza en las facultades intelectuales, que los hace tercos para sostener sus caprichos, soberbios para no reconocer su inferioridad y estado miserable, y tontos para resistir a qualquiera instrucción que se les quiera dar (Lozano, 1809, p. 350). 
Otros estudiosos de la época como Francisco Antonio Zea y principalmente, Manuel del Socorro Rodríguez o Salvador Rizo de quienes se decía eran mulatos, tampoco encontramos que hayan escrito o hecho algo por cambiar la situación de los esclavos neogranadinos (Ortega, 2002, p. 127). Empero, ni el propio Simón Bolívar hasta su viaje a Haití en 1814, después de haber pasado por Jamaica y Trinidad, había contemplado la idea de incluir a los negros esclavos como ciudadanos en su gran proyecto político (Ocampo, 1999, p. 328). Incluso, podría citarse el caso del francés de Riux (radicado en el Nuevo Reino de Granada) quien se ufanaba de sus ideas ilustradas y filantrópicas, pero que a la sazón fue desenmascarado por el mismo Alejandro de Humboldt, al referir en su diario (1801) con gran disgusto, algunos aspectos de la personalidad de este:

[...] De Louis Rieux cuenta que compró la hacienda de la Egipciaca, una plantación de cacao de los Jesuitas con 80 negros. [...] Me pareció indignante como el inmoral Doctor Rieux (el mismo que fue encarcelado largos años a causa de sus ideas revolucionarias, el mismo que en ese entonces hablaba de libertad para los esclavos, y mientras le fue útil representó el papel de ciudadano francés), a sangre fría hacía caer de rodillas, ante sí, a los negros de la Egipciaca. Miserable canalla humana que os hacéis pasar por filósofos en Europa (Von Humboldt, 1982: VII a y b, 11 y 12) 1 .

El único criollo que llegó a proponer la creación de una sociedad de pequeños productores libres, que remplazara la esclavitud en aras de optimizar la producción agrícola, fue el payanés José Ignacio Pombo; sin embargo, lo hizo movido por el temor que le despertaba una revolución como la producida en Haití en el año de 1804 y la misma influencia ejercida por los fisiócratas como Adam Smith, pues Pombo al igual que los demás intelectuales neogranadinos, consideraba a las personas de color como seres inferiores y violentos (Múnera, 1998, p. 108).

A pesar de que las ideas antiesclavistas provinieron del extranjero hacia finales del siglo XVIII en el Nuevo Reino de Granada, estas no fueron asimiladas por el grupo de "notables" neogranadinos, es decir, no fluyeron de "arriba" hacia "abajo", sino por la misma presión que ejercieron las llamadas "castas" o "capas bajas" de la sociedad (negros, mulatos, quinterotes, cuarterones, mestizos, entre muchos otros) hacia la élite neogranadina. Prueba de lo anterior fue la Revolución Comunera de 1781, en especial la "segunda fase" (Aguilera, 1985,

11 A pesar que la influencia del pensamiento romántico-ilustrado europeo (Locke, Hobbes, Montesquieu, Voltaire, Rousseau, etc.) en el grupo de intelectuales criollos no es detectable sino hasta las primeras décadas del siglo XIX, como lo asevera Jaramillo (1968, pp. 235-269); sin embargo, debe anotarse que existió cierta influencia de ideas en el grupo de eruditos criollos con relación a los pensadores de dicha corriente filosófica occidental para finales del siglo XVIII. El aporte ideológico consistió en que los occidentalizados ilustrados en mención también mantuvieron y justificaron la esclavitud de la población africana al considerarla inferior con relación a la europea, como puede apreciarse en el libro de Montesquieu, El espíritu de las leyes ([1748] 1984, Vol. I, libros XVII y XV). Es más, esa mirada de desprecio o de desdén hacia la cultura africana y también americana, es apreciable en el mismo Rousseau, al referirse a estas como pueblos de "bárbaros" o de "salvajes" quienes a su vez no tienen el derecho de decidir sobre su propia libertad, puesto que esta decisión depende única y exclusivamente de las naciones "civilizadas"; es decir, de la cultura occidental (Rousseau, [1753] 1989, pp. 193-287). 
pp. 52-75-127-160) ${ }^{12}$, o la toma del poder de Cartagena de Indias por parte de los negros y mulatos del barrio Getsemaní (durante casi tres años), después de haber obligado al cabildo de la ciudad a proclamar su independencia absoluta el 11 de noviembre de 1811, con relación a la Corona española (Múnera, 1998, pp. 180-207) ${ }^{13}$.

\section{Conclusiones}

- A través de este artículo se estableció que la situación jurídica de la población esclava neogranadina hacia la segunda mitad del siglo XVIII, no tuvo un cambio significativo en sus vidas pese a las disposiciones reales que buscaron protegerla de los abusos de sus propietarios. Este hecho probablemente obedece a la combinación de dos factores: en primera instancia, la fragmentación territorial que impidió la presencia (simbólica y material) de las autoridades virreinales (centrales) en un espacio mayoritariamente rural, lo cual propició la adopción de las normas locales establecidas por la fuerza de la costumbre y en según lugar, a la propia naturaleza de estas disposiciones emitidas por la Corona española, puesto que mantuvieron su carácter punitivo y coercitivo con relación a los esclavos.

- De este modo, los negros esclavos ante la imposibilidad de poder realizar un proyecto vital acorde a sus prácticas y dinámicas culturales, optaron por asumir formas de resistencia ("subrepticias" o "abiertas") ante la sociedad esclavista. Indudablemente las fugas de esclavos que persiguieron la constitución de palenques (la mayoría de estos casos duró poco tiempo), fueron los actos de oposición más importantes hacia el sistema colonial, en donde pudieron recrear un proyecto sociocultural y político, sin la mirada censurante del amo o las autoridades virreinales.

- Con relación a las ideas antiesclavistas que circularon en el Nuevo Reino de Granada provenientes del extranjero hacia finales del siglo XVIII y comienzos del XIX, debe anotarse que fueron los propios negros esclavos o las llamadas "castas" quienes adoptaron e interiorizaron dichas ideas, las cuales probablemente se habían ido cocinando o sedimentando en el transcurso de los casi tres siglos precedentes de esclavitud y no de "arriba" (como en los círculos de estudiosos o ilustrados criollos) hacia "abajo" como pudiera pensarse. Esta hipótesis podría tomar más fuerza y relevancia si se produjeran trabajos inscritos en el plano de la microhistoria, que den cuenta de las construcción ideológica que inspiraron las rebeliones esclavas o la formación de palenque hacia finales del siglo XVIII.

12 La "segunda fase" de la Revolución Comunera, según este autor, se caracterizó por la inclusión de las capas sociales más bajas (blancos pobres, mestizos, indios y esclavos negros, entre otros), perfilándose cada vez más en una lucha decididamente social y anticolonial, en contraste con la "primera fase" la cual fue de carácter policlasista.

13 Este autor sostiene que los negros y mulatos del barrio Getsemaní obligaron a los miembros del cabildo de la ciudad a declarar la independencia de España, porque esta los seguía excluyendo como ciudadanos al ratificarlo así durante las sesiones que se llevaron a cabo entre criollos e ibéricos en la Corte de Cádiz, durante el periodo de expansión napoleónica en España y el vacío de poder que produjo este hecho en sus colonias de ultramar. 


\section{Referencias}

\section{Fuentes documentales}

Archivo General de la Nación-AGN (Bogotá). Negros y Esclavos del Cauca, t. II, ff., 203-456 y t. III, ff.1-265.

AGN (Bogotá). Negros y Esclavos de Bolívar, t. III, ff., 764-875.

\section{Fuentes impresas}

Aguilera, M. (1985). Los Comuneros: Guerra social y lucha anticolonial. Bogotá: Universidad Nacional de Colombia.

Azopardo, I. (1992). Historia del Negro en Colombia. ¿Sumisión o Rebeldía? Bogotá: Editorial Nueva América.

Bastide, R. (1969). Las Américas negras. Las civilizaciones africanas en el Nuevo Mundo. Madrid: Alianza Editorial.

Bauman, Z. (2002). La cultura como praxis. Barcelona: Paidós.

Benavides, F. (2004). El fugitivo de la hacienda: Cimarronismo en la ciudad de Cartago y en la Villa de Santa Cruz de Mompox. Finales del siglo XVIII. Bogotá: Universidad Nacional de Colombia-Sede Bogotá/Instituto Colombiano de Antropología e Historia-ICANH.

Bernand, C. (2000). Negros esclavos y libres en las ciudades hispanoamericanas. Madrid: Fundación Histórica Tavera.

Bowser, F. (1977). El esclavo africano en el Perú colonial, pp. 1524-1650. Colección América Nuestra, América Colonizada, №. 33. México: Siglo XXI.

Brion, D. (1966). El problema de la esclavitud en la cultura occidental. Bogotá: Áncora Editores.

Caldas, Francisco José de. (1808). "Del influjo del clima sobre los seres organizados". En: Semanario del Nuevo Reino de Granada, nº 23 (junio 5).Santafé de Bogotá: Imprenta Real de Santafé.

Charles, M. (1984). El espíritu de las leyes. Vol. I. Madrid: SARPE.

Davidson, D. (1973). "El control de los esclavos negros y su resistencia en el México colonial, pp. 1519-1650". En: Richard Price (coord.), Sociedades Cimarronas: Comunidades esclavas en las Américas. Madrid: Siglo XXI Editores. 
Díaz, R. (2001). Esclavitud, región y ciudad. Bogotá: Centro Editorial Javeriano.

Díaz, R. (2009). "La diversión y lo privado entre los esclavos neogranadinos". En: Borja, Jaime y Rodríguez, Pablo, editores, Historia de la vida privada en Colombia. Vol. I. Bogotá: Editorial Taurus.

Escalante, A. (1954). "El Palenque de San Basilio". En: Divulgaciones Etnográficas del Instituto Etnográfico del Atlántico, Barranquilla: vol. 3, n 5 (diciembre), pp. 207-359.

Fals Borda, O. (1979). Historia doble de la Costa I: Mompox y Loba. Bogotá: Carlos Valencia Editores.

Fogel, Robert \& Engerman, S. (1974). Time on the cross: the economics of American negro slaver. Boston: Brown and Company.

Friedemann, N. (1993). La saga del negro. Bogotá: Instituto de Genética Humana, Universidad Javeriana.

García, Mauricio. (2003). “Apuntes sobre codificación y costumbre en la historia del derecho colombiano". En: Antecedentes. Boletín Jurídico. Cali: Universidad ICESI.

Inikori, J. (1982). Forced Migration. The impact of the export slave trade on African societies. London: Hutchinson University Library.

Jaramillo, J. (1963). "Esclavos y señores en la sociedad colombiana del siglo XVIII". En: Anuario de Historia de la Universidad Nacional de Colombia. Bogotá: U.N..

Jaramillo, U. (1968). "La controversia jurídica y filosófica librada en la Nueva Granada en torno a la liberación de los esclavos". En: Ensayos sobre Historia Social Colombiana, tomo I. Bogotá: U.N.

Klein, H. (1986). La esclavitud africana en América Latina y el Caribe Madrid: Alianza Editorial.

Kuethe, A. (1993). Reforma militar y sociedad en la Nueva Granada, pp. 1773-1808. Bogotá: Banco de la República.

McFarlane, A. (1997). Colombia antes de la Independencia. Economía, sociedad y política bajo el dominio Borbón. Bogotá: Banco de la Republica y Ancora Editores.

Múnera, A. (1998). El fracaso de la Nación, Región, clase y raza en el caribe colombiano, pp. 1717-1810. Bogotá: Banco de la República y Áncora Editores.

Ocampo, J. (1999). El proceso ideológico de la emancipación en Colombia. Bogotá: Editorial Planeta S.A. 
Ortega, C. (2002). Negros, Mulatos y Zambos en Santafé de Bogotá. Sucesos, personajes y anécdotas. Bogotá: Ministerio de Educación Nacional.

Palacios de la Vega, J. (1955). Diario de viajes del padre Joseph Palacios de la Vega entre los indios y negros de la Provincia de Cartagena en el Nuevo Reino de Granada, pp. 1787-1788. Bogotá: A.B.C.

Palacios, J. (1973). La trata de negros por Cartagena de Indias. Tunja: Editorial La Rana y El Águila.

Peñas, D. (1981). La independencia y la mafia colonial: comerciantes, contrabandistas y traidores. Bogotá: Ediciones Tercer Mundo.

Price, R. (1973). Sociedades Cimarronas: Comunidades esclavas rebeldes en las Américas. Madrid: Siglo XXI Editores.

Reis, J., \& Dos Santos Gomes, F. (1996). Liberdade Por un Fio: Histórica dos Quilombos No Brasil. Sau Paulo: Companhia das Letras.

Rodríguez, P. (1981). "La manumisión en Popayán, pp. 1800-1851". En: Revista de Extensión Cultural de la Universidad Nacional. Bogotá: Departamento de Historia de la Universidad Nacional.

Rodríguez, P. (1997). Sentimientos y vida familiar en la Nuevo Reino de Granada siglo XVII. Bogotá: Ariel.

Rousseau, J. J. (1989). Discurso sobre el origen y los fundamentos de la desigualdad entre los hombres. Madrid: Alianza.

Tadeo, L. (1809). "Fragmento de una obra titulada: Fauna cundinamarquesa, o descripción de los animales del Nuevo Reyno de Granada; su autor D. Jorge Tadeo Lozano Maldonado de Mendoza, individuo de la Real Expedición Botánica y encargado con Real aprobación de su parte Zoológica". En: Semanario del Nuevo Reino de Granada, No. 48, (dic. 3). Santafé de Bogotá: Imprenta Real de Santafé de Bogotá.

Taussig, M. (1979). "Religión de esclavos y la creación de un campesinado en el valle del río Cauca, Colombia." En: Estudios rurales latinoamericanos. Bogotá: vol. $^{\circ} 2, \mathrm{n}^{\circ}$ 3, (septiembre-diciembre), pp. 362-390.

Tovar, H. (1992). De una Chispa se forma una hoguera: esclavitud, insubordinación y liberación. Tunja: Editorial de la Universidad Pedagógica y Tecnológica de Colombia.

Von Humboldt, A. (1982). Alexander Von Humboldt en Colombia, extractos de sus diarios. Bogotá: Academia Colombiana de Ciencias Exactas, Físicas y Naturales y Academia de Ciencias de la República Democrática Alemana.

Zuluaga, F. (1986). “Clientelismo y guerrillas en el Valle del Patía”. En: Jaramillo, Jaime (comp.). La Independencia: Ensayos de Historia Social. Bogotá: Colcultura. 